\section{Gas Chromatography Discussion Group}

$\mathrm{T}$ HE annual general meeting of the Gas Chromatography Discussion Group of the Institute of Petroleum Hydrocarbon Research Group was held in the Glazebrook Hall of the National Physical Laboratory on March 16 and was followed by an informal symposium attended by about two hundred members and guests. The report of the Committee for the past year records that the membership of the Group is now approaching five hundred, and the weight of work which this growth has imposed on the honorary officers has led the Committee to look favourably on an offer by the Institute of Petroleum to assume responsibility for a large part of the routine administration of the Group. On the recommendation of the Committee the meeting agreed that this offer should be accepted. Besides the two informal symposia, and preparations for the international meeting in Hamburg, the main activity of the Group during the past year has been the preparation of Gas Chromatography Abstracts, which is distributed quarterly to members; the bound volume for 1960 has been available for some time and that for 1961 will be published shortly.

Introducing the informal symposium which followed, Dr. J. S. Anderson, director of the National Chemical Laboratory, welcomed the meeting to Teddington and made some monitory remarks on the organization of scientific societies. In the first paper Dr. G. A. P. Tuey gave details of the improvements made in the preparative apparatus described at the Amsterdam symposium by Atkinson and himself. Metal columns had been substituted for the glass ones used originally, since the use of an all-metal apparatus made the elimination of leaks easier; Ermeto compression type joints had proved satisfactory. The 1-m. by 1-in. diameter columns were joined by capillary U-tubes which served the same purpose as the mixing washers recommended by Golay for use in large columns. A katharometer designed for analytical use had proved unsuitable as a detector because of the peak reversal which occurred at high flow-rates; attempts to pass part only of the effluent through the katharometer were also unsatisfactory because the proportioning did not remain constant for all peaks, and in addition the throttle was liable to canse condensation of vapour as a result of adiabatic cooling and consequently an unsteady base-line. The best form of katharometer for this application was one with transverse sensing wires ablo to accept tho total gas flow, such as had been used in the University of Birmingham. It appears from various authors that, with appropriate sample size, an H.E.T.P. of $3-5 \mathrm{~mm}$. may be obtained in columns up to $50-\mathrm{mm}$. diameter. Recent work on H.E.T.P. as a function of flow-rate in these preparative columns somewhat surprisingly yielded S-shaped curves, of which one limb tended towards the origin at low rates of flow, in place of the normal U-shape. When the results were used to compare the parameters H.E.T.P., Resolution and $S$ (suggested by Purnell), the last was found to be independent of sample size and was therefore considered a better paramoter than the other two for characterizing a column. In discussion Dr. H. Boer and Mr, D. H. Desty emphasized the value of the cross-section detector in preparative work because it had a linear response up to almost 100 per cont vapour. In reply to a question, Dr. Tuey stated that the highest sample recovery was obtained by scrubbing the gas with a solvent or a reagent; an electrostatic precipitator was liable to causo chemical change.

Dr. J. N. A. Ridyard discussed the linearity and response of the flame ionization detector. 'The upper limit of linearity is generally given as $10^{-8} \mathrm{amp}$., corresponding to a mean flow of about $2 \mu \mathrm{gm}$./sec. for a 1-mgm. sample on an ordinary analytical packed column. Ridyard investigated the effect of varying the operating conditions and used a computer to derive contour maps of the response at 1 and 10 per cent non-linearity as functions of the hydrogen and nitrogen flow-rates, the height of the probe above the jet and the diameter of the jet. There was generally an optimum position for the probe and a longer linear range was obtained if the probe was negative with respect to the jet. There were optimum rates of flow of both hydrogen and nitrogen, and this last point was confirmed in discussion by Dr. $R$. Kaiser.

Dr. E. Heine described the use of packed capillary columns, an interesting innovation in technique which is suitable for the separation of low-boiling hydrocarbons. The columns are made of glass drawn out in the usual way in the machine described by Desty. The tubing (2-mm. internal diameter) which is used, however, has first a clean wire $1-\mathrm{mm}$. diameter placed in it centrally and the annular space is then packed with powdered adsorbent (alumina, $0 \cdot 1-0 \cdot 15-\mathrm{mm}$. diameter, prepared by baking at $400^{\circ} \mathrm{C}$. for $9 \mathrm{hr}$.) so that as the column is drawn the adsorbent moves with the glass and sticks to the inner wall of the capillary, which is about $0.3 \mathrm{~mm}$. in diameter. Before use the column is flushed with dry hydrogen for a day at $120^{\circ}$. Heine showed chromatograms of highspeed separations of gaseous mixtures which he had obtained on these columns; in one example, obtained on a 2-m. column at $90^{\circ} \mathrm{C}$., complete separation of the ethane/cthylene and propane/propylene peaks had been obtained; in another, 15 saturated and unsaturated hydrocarbons up to $\mathrm{C}_{4}$ had been separated at $80^{\circ} \mathrm{C}$. The method of aqueous doactivation to adjust selectivity, suggested by C. G. Scott, could be used with these columns; if carrier gas containing a suitable concentration of water was passed into the column, equilibrium was reached in a few hours. On close examination irregularities in the packing were obvious, but despite this the column performance was good, prosumably because the sequence of narrow gas passages and empty spaces between the grains allowed quick mass transfer between the phases. In discussion Mr. C. $\mathrm{G}$. Scott commented that he had tried to make similar columns but found them too fragile because of the strains set up in the glass by the adhering particles of alumina; there is evidently some know-how in question here which remained unexplained to the meeting. Dr. A. Goldup spoke as a protagonist of liquid-coated capillaries and showed a chromatogram obtained on a $2-\mathrm{m}$. column, 0.002 in. diameter, coated with squalane, in which a gaseous mixture, similar to one quoted by Heine, had been separated in 5 sec. Mr. D. H. Desty mentioned his attempt to make a regularly packed capillary column by drawing and twisting wire.

Dr. 'T. R. Phillips, in describing the separation and analysis of the isotopes of hydrogen, directed attention to the possibility that the displacement technique might yet find a use in modern gas chromatography, since the method offers the advantages of greater capacity for a given-sized column and that the sample is not contaminated by carrier gas. This last state- 
ment appears somewhat paradoxical because it is generally put in the opposite sense in favour of elution chromatography. It may, however, be justifiable in respect of preparative gas chromatography since in this technique one of the grestest problems has been the separation of vapours at low partial pressures from large amounts of carrier gas, and it may be advantageous to avoid the use of a carrier in some circumstances. Phillips has separated hydrogen and deuterium on columns containing molecular sieve $5 \AA$. in a method which is effectively one of selfdisplacement. The order of elution is first hydrogen, second deuterium (the opposite to that obtained by Glueckauf and Kitt in their separations on palladium black) and the method is useful for removing small quantities of hydrogen from deuterium-rich mixtures. Up to $300 \mathrm{ml}$. of sample was passed into the column cooled in liquid nitrogen; the Dewar vessel containing the liquid nitrogen was gradually lowered and the sample itself displaced the hydrogen, which was then followed by the deuterium. At the end of each run the column was filled with deuterium and there was no need to remove this before admitting the next sample; there was thus no need for evacuation of the column or for a carrier gas. Tests showed that molecular sieve had no tendency to promote the formation of $\mathrm{HD}$ molecules.

Dr. P. G. Jeffery described the application of gas chromatography to the analysis of gases obtained from rocks and minerals. The rocks he had examined were mostly silicates and these yielded small quantities of carbon dioxide when boiled with dilute phosphoric acid. The reaction had been carried out in a $10-\mathrm{ml}$. flask on powdered samples of up to $1 \mathrm{gm}$., and the gas evolved was analysed on columns containing silica gel or activated carbon. The method enabled concentrations as low as 5 p.p.m. to be determined, or, on the other hand, enabled analyses to be made on very small samples, as, for example, when rocks had been hand-sorted under the microscope, if the concentrations were higher. The same method had been used for determining the carbon dioxide content and nitrous oxide content of monoethanolamine solutions. Attempts were also being made to determ. ine the water which is present to the extent of 2-20 per cent in most rocks, either on the surface of the mineral grains, chemically combined, or as hydroxyl ions held by weak forces between the layers of minerals with sheet structures. The water was driven off by fusing the sample in a silica tube with a suitable flux (for example, a 50/50 mixture of sodium tung. state and borax glass) at temperatures up to $700^{\circ} \mathrm{C}$. In early experiments the water had been allowed to react with calcium carbide, but later it was found more satisfactory to determine it directly on a polyethylene glycol column. The method was calibrated by using samples of rocks containing known concentrations of water; in fact it had proved difficult to ensure the liberation of all the water from the samples and there were side reactions which removed water. Other gases, for example, helium from pitchblende, had also been determined by heating rock samples, and in this way hydrogen, helium, argon, oxygen, nitrogen and carbon monoxide had all been obtained from silicate rocks. The volume of the gases was greater than the free space and their presence could only be accounted for by some kind of adsorption. The novelty of this application of gas chromatography aroused considerable interest and many in the audience were intrigued by Jeffery's claim to have found hydrocarbons (even though only to the extent of a few p.p.m.) in granite.

The last paper of the meeting was given by Dr. R. P. W. Scott on resistance to mass transfer in capillary columns. Golay derived an expression for H.E.T.P. in terms of solute and column parameters, but experimentally it has been found that values of H.E.T.P. are significantly higher than those given by the equation. Khan suggested a theory to explain the difference in which he postulated another effect, the interfacial resistance to mass transfer. Scott had tried to determine the reality of this effect; the experiments and their mathematical analysis were designed to distinguish between the effects of all the factors taken account of in the Golay equation. A column consisting of $100 \mathrm{ft}$. of nylon capillary $0 \cdot 020$-in. diameter was used, and H.E.T.P.'s were determined at different film thicknesses (from zero upwards) and gas velocities for samples of $n$-heptane on dinonyl phthalate with argon as carrier gas. In this system Khan's factor was not found to be significant, but it might well be when a more polar solute is in question. What did appear to be a significant cause of departures from the Golay equation was a factor associated with the wall of the column, presumably adsorption.

D. Ambrose

\section{VEB CARL ZEISS, JENA}

\section{GOLDEN JUBILEE OF WORK ON AIDS TO VISION}

$\mathrm{F}$ OLLOWING a long period of scientific preparatory work the Zeiss Works at Jena organized, fifty years ago, the 'Ophthalmo'-Department and began the manufacture of ophthalmic lenses, including specific types of aids to vision as well as ophthalmological instruments.

This article reviews the development of that Department during the past five decades and the considerable extent to which Jena instruments and aids to vision were able to share in the world's progress in ophthalmology and in the sphere of ophthalmic optics.

Despite their manifold drawbacks, the flat forms of spectacle lenses-bounded by like surfaces on both sides-actually retained that form for more than a period of six hundred years; and this in face of the fact that meniscus-shaped lenses were suggested as early as in the eighteenth century and that time and again after 1800, W.H. Wollaston and L.J. Schleiermacher in 1842 directed attention to the theoretical importance of rotation of the eye. A few firms produced plano-lenses and, in a few instances, even meniscus lenses on the strength of empirical experiments and, for the correction of astigmatic eyes, spectacle lenses with torical surfaces. However, mercenary motives proved strong enough to override any of these beneficial suggestions, thus permitting the inefficient equilateral lenses and cylinder lenses to hold their own. 